OPEN ACCESS

Edited by:

Tien Ming Lee,

Sun Yat-sen University, China

Reviewed by:

Andres Garcia

National Autonomous University of

Mexico, Mexico

Jared D. Margulies,

University of Alabama, United States

*Correspondence:

Tom P. Moorhouse

tom.moorhouse@zoo.ox.ac.uk

Specialty section:

This article was submitted to

Conservation and Restoration

Ecology,

a section of the journa

Frontiers in Ecology and Evolution

Received: 23 September 2020

Accepted: 15 January 2021

Published: 17 February 2021

Citation:

Moorhouse TP, D'Cruze NC and Macdonald DW (2021) Information

About Zoonotic Disease Risks Reduces Desire to Own Exotic Pets

Among Global Consumers.

Front. Ecol. Evol. 9:609547.

doi: 10.3389/fevo.2021.609547

\section{Information About Zoonotic Disease Risks Reduces Desire to Own Exotic Pets Among Global Consumers}

\author{
Tom P. Moorhouse ${ }^{1 *}$, Neil C. D'Cruze ${ }^{1,2}$ and David W. Macdonald ${ }^{1}$ \\ ${ }^{1}$ Wildlife Conservation Research Unit, Department of Zoology, Recanati-Kaplan Centre, University of Oxford, Oxford, \\ United Kingdom, ${ }^{2}$ World Animal Protection, London, United Kingdom
}

Demand for exotic pets is a substantial driver of the illegal wildlife trade. Previous work has suggested that this demand could be reduced by conservation marketing messaging highlighting the potential consequences to individual purchasers, in the form of zoonotic disease risks, or legal ramifications. Such work, however, has been limited only to respondents from culturally Western countries, and has not accounted for how underlying attitudes to the keeping of exotic pets may influence desire to own one, or affect the effectiveness of demand reduction messaging. We surveyed 1,000 respondents in each of Brazil, China, USA and Vietnam, showing each five mammal, bird, and reptile pets in random order. Each pet was accompanied with either a "control" statement, describing the species' diet, or one of four types of "treatment" statement describing zoonotic disease, animal welfare, legal or species conservation consequences. Respondents were asked to rate how much they would like to own the pet on a 1-10 scale. All respondents demonstrated decreased desire to own a given exotic when shown any of the types of treatment information, but disease information provoked the greatest decrease, relative to controls (a mean decrease of $26.9 \%$, compared with 16.2, 17.9, and 18.9\% for legality, welfare and conservation information, respectively). We also found that respondents with the highest stated likelihood of purchasing pets possessed a series of beliefs that could facilitate this purchase while maintaining an ethical self-image: in particular they believed that shops were well-regulated, and that they were able to distinguish captively-bred from wild caught animals. In summary all respondents of any nationality were motivated particularly to avoid the risk of zoonotic disease, and we recommend that demand reduction campaigns leverage this desire, particularly in the new context of COVID-19.

Keywords: zoonotic disease, experimental survey, social marketing, demand reduction, exotic pet

\section{INTRODUCTION}

Recent decades have witnessed a substantial increase in the keeping of exotic (non-domesticated) companion animals (Grant et al., 2017; Ribeiro et al., 2019; Lenzi et al., 2020). Demand for exotic pets accounts for almost a fifth of global wildlife trade reports (Baker et al., 2013) making them a key driver of a global wildlife trade that is worth (excluding fisheries and timber) an estimated \$30.642.8 billion annually, of which $\sim \$ 22.8$ billion is legal (Engler and Parry-Jones, 2007), and \$7.8-20 billion illegal (Haken, 2011; Pires and Moreto, 2011). Many of the exotic pets bought by consumers are sourced from wild populations (Bush et al., 2014; Harrington, 2015) after being poached 
from the wild (Pires and Moreto, 2011) and then distributed through criminal organizations to consumers (Engler and ParryJones, 2007; Dalberg, 2012; Ayling, 2013). While captive breeding facilities meet some of the global demand for pets, many launder wild-caught individuals into the captive-bred market (Nijman and Shepherd, 2009; TRAFFIC International, 2012). As a consequence, purchasers of exotic pets in consumer regions support, whether knowingly or not, the illegal trade in wildlife (TRAFFIC International, 2012) — and thereby a substantial, and growing, threat to global biodiversity, species conservation and animal welfare (Sodhi et al., 2004; Grieser-Johns and Thomson, 2005; Pires and Moreto, 2011; Fernandes-Ferreira et al., 2012; Baker et al., 2013; Dutton et al., 2013; Challender et al., 2015).

Efforts to stem illegal and/or unsustainable wildlife trade have traditionally focussed on tackling the supply of products, through enforcement and regulation (Veríssimo et al., 2012; Challender and MacMillan, 2014). There is, however, an increasing, additional, focus on measures to reduce consumer demand through educational and public awareness campaigns (Courchamp et al., 2006; Dalberg, 2012; Baker et al., 2013; Veríssimo and Wan, 2019). At present the relative effectiveness of demand reduction approaches often remains untested and under-reported (Olmedo et al., 2018; Veríssimo et al., 2018; Veríssimo and Wan, 2019). To be effective campaigns must understand the factors that influence customers' behavior, and deliver the correct message through the right communications medium (Dalberg, 2012; Challender et al., 2015). While a lack of information can be a barrier to changing behavior (Schultz, 2002), not all information will motivate individuals to alter their behavior (Stern, 2000). As an example, Moorhouse et al. (2017a) demonstrated that consumers' desire to purchase exotic pets was reduced by $39 \%$ by the provision of information concerning the negative legal and zoonotic disease consequences of purchasing exotic animals, but not by messages about the negative welfare or conservation consequences for the animals. Moorhouse et al. (2017a) concluded that information campaigns could be useful to reduce demand for exotic pets, or redirect demand onto non-exotic species, or those sourced from rescue centers or legitimate captive breeders, likely to be most successful through leveraging consumers' desire to avoid zoonotic disease and/or legal consequences.

A key limitation of the above study was that $90 \%$ of its respondents derived from only a relatively small number of principally English-speaking countries: the USA, UK, Australia and Canada, with $10 \%$ from eight other countries or of unknown origin. Attitudes toward wildlife (Tao et al., 2004; Cong et al., 2014) and responses to demand reduction messaging surrounding the ownership and use of that wildlife (Moorhouse et al., 2017b, 2019) can vary between nationalities and so it is unknown whether Moorhouse et al. (2017a) findings may be applicable outside of these countries. While there are no exact figures on patterns of global exotic pet ownership, the exotic pet market is known to be expanding rapidly as living standards improve in regions such as Asia and South America (Ding et al., 2008; McNeely et al., 2009; da Nóbrega Alves et al., 2010). For example the compound growth rate of China's pet industry was $49.1 \%$ from 2010 to 2016 , the fastest among all industries, attributed to the population's increasing wealth (Yiwei, 2020). Principal consuming regions for the global wildlife trade are the United States, the Middle East, South East Asia, South America and the European Union (Haken, 2011; Bush et al., 2014) and insofar as exotic ownership is a driver of this trade, the attitudesand their amenability to change-of a substantial proportion of consumers of exotic pets therefore remains untested.

In this study we employ an experimental survey to assess the potential for demand reduction messages to influence the desire of respondents to buy exotic pets of respondents in Brazil, China, and Vietnam, as representatives of key consuming regions. We also analyse the demographic factors that correlate with respondents' desire to own exotics, and examine whether this desire influences the effectiveness of treatment messaging or respondents' attitudes and beliefs regarding the impacts of exotic pet ownership.

\section{METHODS}

We surveyed 4,000 respondents, comprising 1,000 from each of Brazil, China, the USA and Vietnam. Respondents from the USA were included to permit comparison with results from Moorhouse et al. (2017a). Our sample size in each country was sufficient to meet the statistical power required for our experimental design. All questions were professionally translated from English into respondents' local language, and translations independently verified by native speakers. All questions were presented to all respondents: they answered six initial questions about their sex, age, educational level, income, occupation and household composition (whether respondents lived alone, with adults, or with children under 15 years of age). They were then asked "How do you feel about exotic pets?"-which we defined as "animals that are traditionally not domesticated for farming or in the house in close interaction with humans"-and asked to select one response from: "I have never owned an exotic pet and don't want to," "I have never owned an exotic pet but would like to," "I own at least one exotic pet" and "I have previously owned an exotic pet but don't at the moment." Respondents who stated either that they had previously or currently, or would like to, own a pet, were then asked "How likely are you to buy an exotic pet in the next 2 years?" with options "Very likely," "Quite likely," "Neither likely nor unlikely," "Quite unlikely" and "Very unlikely."

Following these questions all respondents were shown the statement: "We're going to show you a series of exotic pets, with some information about each one. Some of the information may not be true about the pet, but for this exercise please assume that it is, and based on the information you are given, say how interested you would be in owning this" and sequentially shown 15 different pets, each accompanied by information about it. The identity of each pet was randomly selected from eight mammals, eight birds and eight reptiles, with five of each shown to any given respondent. Information for any pet was randomly selected from five possible types, of which one was control information and four types were treatment information. Control information comprised information about 


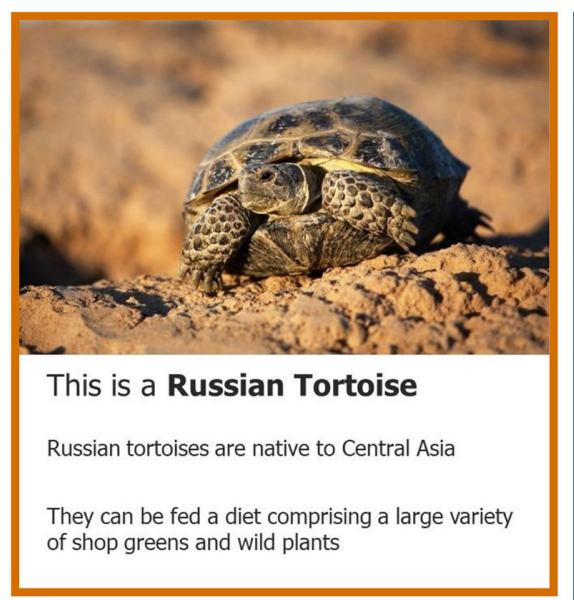



This is a Russian Tortoise

Russian tortoises are native to Central Asia

They can carry diseases that infect humans, including cryptosporidium and intestinal parasites

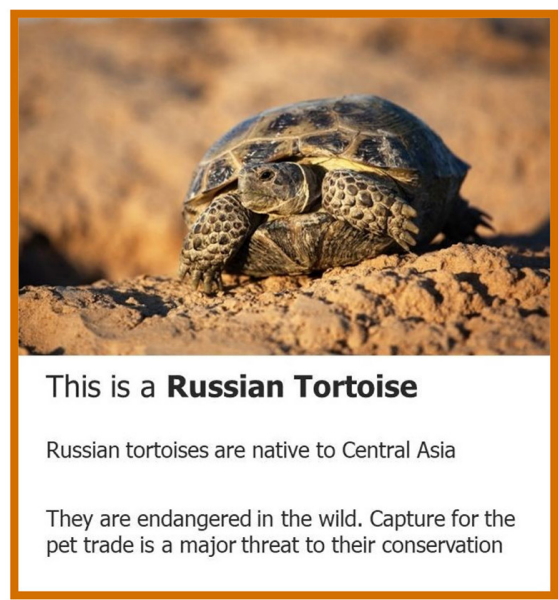



This is a Russian Tortoise

Russian tortoises are native to Central Asia

They are often transported for sale in conditions that cause severe welfare issues and deaths

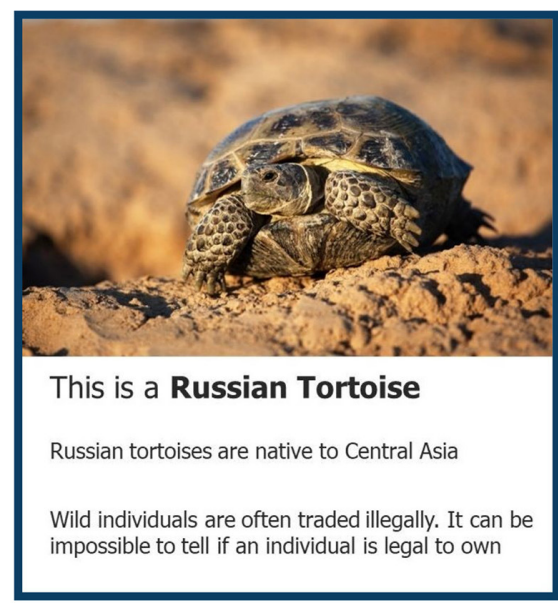

FIGURE 1 | An example set of control and treatment statements for one species, the Russian tortoise, Testudo horsfieldii. From left to right, top to bottom are control, disease, welfare, legality, and conservation information statements.

the pet's diet in captivity (Supplementary Table 1; Figure 1). Treatment information comprised text outlining the potential negative impacts of owning the pet for human disease/human harm, animal welfare, and the conservation status of the pet's wild populations, as well as the negative legal consequences of owning the pet (Supplementary Table 1; Figure 1). For any given pet all information presented was accurate [see Moorhouse et al., 2017a], with a small number of exceptions: of 120 statements (five statements for each of 24 different pets), 102 were accurate, and 18 were fabricated. Fabricated statements may or may not have been true (we found no evidence to support them, but they were nonetheless likely to be true-for example individuals from the majority of pet reptile species are likely to act as reservoirs for cryptosporidium; Supplementary Table 1), but were designed to sound plausible. These instances are highlighted in Supplementary Table 1. A further four statements were augmented with an additional word (again highlighted). This limited use of non-verified statements was required to permit full availability of control and treatment information across all experimental treatments-this in turn allowed for a balanced experimental design, minimizing the number of species required to deliver complete tests of each experimental treatment. For each pet/information combination respondents were asked to select a response from an eleven-point Likert-type scale (from 1 - "I would never want to own this"- to 10- "I would definitely want to own this") before being shown the next pet.

Once all pets were rated, we asked respondents-from the USA and Brazil only, because respondents from China and Vietnam were required to participate in a further survey, the results from which are published elsewhere [see Moorhouse et al. (2020)] — to rate their level of agreement with eleven attitudinal statements divided across five broad, non-exclusive subject areas: (1) the likely source of exotic pets (wild caught or captively bred); (2) the degree of regulation of the market for exotic pets (3) consumer responsibilities (4) conservation impacts and; (5) welfare impacts (Table 1).

Statements within these subject areas were presented in random order. Ratings were made on a ten-point Likert-type scale, ranging from $1=$ Disagree strongly to $10=$ Agree strongly. Respondents from China and Vietnam were not asked to rate 
TABLE 1 | Attitudinal statements, and the effect of respondents' stated likelihood of future purchase on their level of agreement with these figures.

\begin{tabular}{|c|c|c|c|c|c|}
\hline Category & Statement & Estimate & Wald Z & $P$-value & Odds-ratio \\
\hline Source of pet & $\begin{array}{l}\text { I'm not worried about buying a pet that was caught } \\
\text { from the wild }\end{array}$ & 0.292 & 11.3 & $<0.001$ & 4.30 \\
\hline Source of pet & I can tell if an animal for sale was bred in captivity & 0.344 & 14.1 & $<0.001$ & 5.58 \\
\hline Market regulation & $\begin{array}{l}\text { If buying exotic pets was bad for conservation shops } \\
\text { wouldn't be allowed to sell them }\end{array}$ & 0.226 & 9.67 & $<0.001$ & 3.10 \\
\hline Market regulation & $\begin{array}{l}\text { If buying exotic pets was bad for animal welfare } \\
\text { shops wouldn't be allowed to sell them }\end{array}$ & 0.246 & 10.5 & $<0.001$ & 3.42 \\
\hline Market regulation & $\begin{array}{l}\text { I can trust traders not to sell animals from illegal } \\
\text { sources }\end{array}$ & 0.357 & 13.9 & $<0.001$ & 5.97 \\
\hline Consumer responsibility & $\begin{array}{l}\text { It is not my responsibility to make sure exotic pets } \\
\text { come from a sustainable source }\end{array}$ & 0.127 & 5.27 & $<0.001$ & 1.88 \\
\hline Consumer responsibility & $\begin{array}{l}\text { People have a duty to make sure they don't buy pets } \\
\text { that come from the wild }\end{array}$ & 0.161 & -6.67 & $<0.001$ & 0.447 \\
\hline Conservation impacts & Buying exotic pets could be bad for conservation & 0.149 & -6.10 & $<0.001$ & 0.474 \\
\hline Conservation impacts & $\begin{array}{l}\text { I'm not worried if buying exotic pets decreases wild } \\
\text { populations }\end{array}$ & 0.228 & 8.47 & $<0.001$ & 3.13 \\
\hline Welfare impacts & $\begin{array}{l}\text { I can give an exotic pet a better life than it would } \\
\text { have in the wild }\end{array}$ & 0.406 & 15.6 & $<0.001$ & 7.61 \\
\hline Welfare impacts & Buying exotic pets could be bad for their welfare & 0.166 & -6.52 & $<0.001$ & 0.444 \\
\hline
\end{tabular}

Statistics given to 3 significant. Wald Z-test statistics are reported from models that also included the effect of respondents' age, sex, and nationality.

these statements, but were instead presented with another series of questions on a different topic [of traditional medicinal usage; see Moorhouse et al. (2020)], their answers to which would have been influenced by these attitudinal questions.

The survey was conducted in September 2018 and designed in collaboration with, and conducted by, a professional market-research company (Touchstone Partners Limited, http:// www.touchstonepartners.co.uk) who coordinated respondent recruitment online through proprietary market research panels. Our sample size of 4,000 respondents was achieved after removing those who took less than one third of the median response time (a market research industry standard action to exclude disengaged respondents), and replacing these with additional respondents until the desired sample size was reached. Panelists were familiar with online surveys but not contacted so frequently as to have become unrepresentative of the wider population. All research was subject to ethical approval, references R57894/RE001, Oxford University CUREC.

\section{Statistical Analysis}

Initially we wished to understand what demographic factors might be associated with respondents' stated likelihood of purchasing an exotic pet in the future. We conducted an ordinal logistic regression analysis (implemented in Program R; Christensen, 2015; Christensen and Christensen, 2015) with a response variable derived from respondents' answers to the questions of "How do you feel about exotic pets" and the followup "How likely are you to buy an exotic pet in the next 2 years?" to create a six-point Likert-type scale. The lowest score (1) was awarded to the response "I have never owned an exotic pet but would like to" to the initial question, and then responses to the follow-up question were rated from 2 (="Very unlikely") to 6 (="Very likely") to construct a single metric ranging from
1 (=non-purchase) to 6 (="very likely" to purchase). Available explanatory variables were respondents' age, sex, country or origin, level of education (six point scale from "high school certificate" to " $\mathrm{PhD}$ "), their relative income (a seven point scale in local currency), whether they had previously owned an exotic pet, and whether they had children under the age of 15 living in their house (included to discern the extent to which the presence of children was a motivation for adults to buy exotics).

We assessed the effect of the experimental treatment on desire to own each pet using repeated measures ordinal logistic regression (Christensen, 2015; Christensen and Christensen, 2015). We analyzed each taxon (mammals, birds, reptiles) separately, because, a priori, different taxa may have different levels of attractiveness for respondents from different countries, arising from cultural norms (e.g., Herzog, 2014; Statista, 2016), which could potentially affect responses to treatment messaging. For each analysis, therefore, the response variable was respondents' selected desire to own (a 1-10 Likert-type scale) each of five pets from a given taxon. Available explanatory variables were respondents' age (entered as a covariate), sex, country, education, treatment (a factor with five levels encoding the type of information accompanying each pet for a given respondent: control, conservation, disease, legality, welfare), education-level and the identity of each animal. We also included respondents' previously stated likelihood of purchasing an exotic (on a 1-6 scale) as a covariate, because this was likely to correlate both with their desire to possess a given animal, but also their response to treatment information. We included, $a$ priori, an interaction between purchase likelihood and treatment to test for this effect. We also included a variable encoding the order in which each animal, with its accompanying information, was shown to the respondent in question (a covariate with a value of 1-15 where 1 was the first animal shown, 15 the 
TABLE 2 | Factors affecting respondents' stated likelihood of purchasing an exotic pet in the new 2 years.

\begin{tabular}{lccc}
\hline Source & d.f. & LR statistic & $\boldsymbol{P}$ \\
\hline Age & 1 & 350 & $<0.001$ \\
Sex & 1 & 2.66 & 0.103 \\
Country & 3 & 90.96 & $<0.001$ \\
Education & 1 & 3.57 & 0.0590 \\
Relative income & 1 & 26.2 & $<0.001$ \\
Prior ownership & 1 & 1143 & $<0.001$ \\
Children under 15 & 1 & 25.2 & $<0.001$ \\
\hline
\end{tabular}

Statistics given to 3 significant figures.

last). This was included to account for the possibility that the repetition of treatment messages for each respondent may alter the effectiveness of different types of treatment information. We included the interaction of treatment*order to test whether the size and direction of the effect of treatment information might vary with repetition of treatment information. See Table 2 for a full list of explanatory variables.

We analyzed factors affecting the responses of participants from the USA and Brazil to the follow-up attitudinal questions using separate single measure ordinal logistic regression analysis for each statement $(n=11)$. Available explanatory variables were respondents' age, sex, country, education and income, and their previously stated likelihood of purchasing exotic pets (entered as a covariate, see Table $\mathbf{1}$ ).

\section{RESULTS \\ Overview}

We received full responses from 4,000 respondents, with 1,000 respondents from each of Brazil, China, the USA, and Vietnam for the 2018 survey. Exceptions to this were to the attitudinal questions, for which we elicited and received responses only from 2,000 respondents from the USA and Brazil.

\section{Likelihood of Future Purchase}

Likelihoods of purchasing exotic pets in the future varied between respondents' country of origin (Table 2), such that overall Chinese respondents were approximately half as likely to select higher purchase likelihoods than were respondents from Brazil, the reference level (post-hoc Wald test, $\mathrm{z}=-6.494, P<0.01$; odds ratio $=0.55)$. Respondents from the USA had equal likelihoods of future purchase to Brazilian respondents (post-hoc Wald test, $\mathrm{z}=-0.835, P=0.404$ ) while respondents from Vietnam were marginally more likely to select higher purchase likelihoods than those from the USA or Brazil (Wald test, $\mathrm{Z}=2.003, P=0.045$; odds ratio $=1.19$ ) .

Respondents who had already owned an exotic were over nine times more likely to select a higher likelihood of purchasing one in the future than were respondents who had not (Table 2; odds ratio for the effect of prior ownership $=9.34$ ). Of prior owners $77.3 \%$ stated that they were "quite likely" or "very likely" to buy an exotic, vs. $24.8 \%$ of those who had never owned an exotic.
Conversely, $54.1 \%$ of non-owners stated they did not want to buy an exotic, vs. $0 \%$ of prior owners. Respondents' country and prior ownership were, however, partially conflated, such that $44.7 \%$ of Brazilian and $48.4 \%$ of Vietnamese respondents stated they had owned an exotic at some point, whereas in the USA and China these figures were 35.7 and $30.3 \%$, respectively.

Older respondents selected lower future purchase likelihoods than did younger respondents. Of respondents under $34(n=$ 1,994), 56.8\% stated they were "quite likely" or "very likely" to purchase an exotic in the future, and $21.1 \%$ stated they did not want to buy one. For respondents over $55(n=424)$ these figures were $15.8 \%$ (likely) and $64.4 \%$ (did not want), respectively. Respondents with children in the home were 1.39 times more likely to select higher purchase likelihoods.

\section{Effect of Experimental Treatment on Desire to Own}

Respondents shown images of exotic pets accompanied by any type of treatment information selected a lower desire to own them than respondents shown the same images and control information (Figure 2). With control information, respondents' mean selected desire to own any animal (on a 1-10 scale) was 3.50 (s.d. 3.50) for mammals, 5.09 (s.d. 3.71) for birds and 3.05 (s.d. 3.47) for reptiles (Figure 2). When presented with treatment information these figures were 2.79 (3.33) for mammals, 4.04 (3.76) for birds and 2.49 (3.25) for reptiles, such that desire to own was $17.8,16.1$, and $18.3 \%$ lower, respectively (Tables 3A-C) in separate analysis of each taxon (Figure 2).

Wald tests for the effect of levels of treatment (disease, legality, welfare, conservation) revealed that disease information provoked a greater decrease, relative to controls, than did legality, welfare or conservation information (Figure 2): respondents' mean selected desire to own was lower by $27.2 \%$ (mammals), $25.5 \%$ (birds), and $28.1 \%$ (reptiles) when shown disease statements, but decreases relative to controls were smaller when respondents were shown legality $(16.3,15.2,16.7 \%$ lower for mammals, birds, reptiles, respectively), welfare (18.1, 17.2, 18.5\%) or conservation $(20.0,15.9,19.8 \%)$ statements (Wald tests for relative effect of disease, compared with legality, welfare and conservation $\mathrm{Z}>5.92, P<0.01$ for all taxa and treatment levels; Figure 2). There was no consistent evidence across different taxa of any substantial difference in the size of the effect of the remaining treatment levels (legality, welfare, conservation): across all taxa and statements the maximum difference in desire to own was 3.2\% (Figure 2).

Respondents' selected desire to own a given pet was strongly correlated with their previously stated likelihood of future purchase (Figure 3). For mammals, mean desire to own increased from 1.08 (s.d. 2.17) to 5.07 (3.61); for birds these figures were $1.94(2.90)$ to 6.57 (3.44), and reptiles 0.870 (2.00) to 4.69 (3.72). The relative effectiveness of treatment statements, however, did not vary with likelihood of future purchase in models in which this interaction term was entered (LRT effect of treatment*likelihood of purchase $<4.5026, p>0.3422$ in all analyses). 


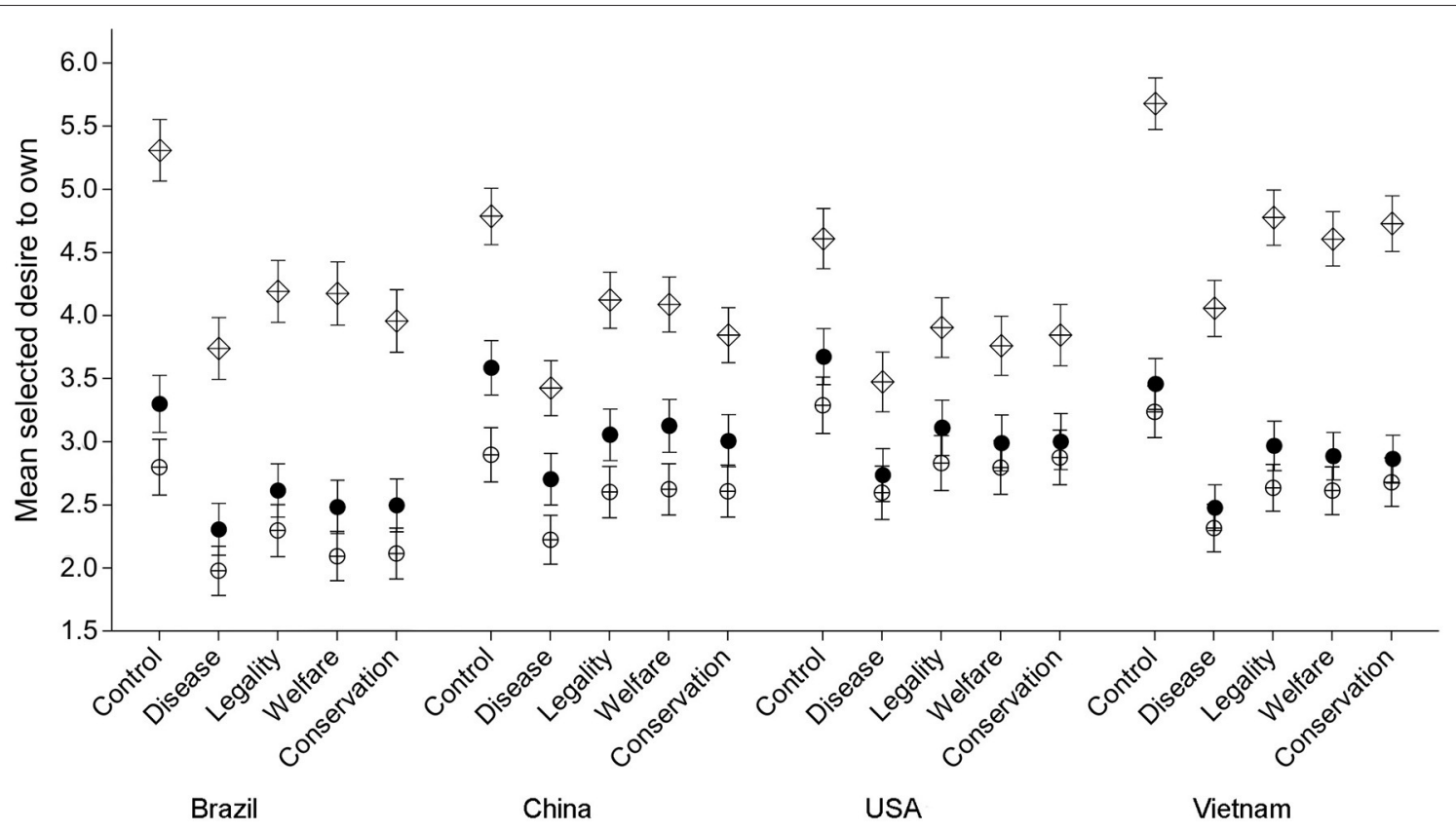

FIGURE 2 | The mean desire to own a given pet, on a 1-10 scale, of respondents from each country, given each type of experimental treatment, for birds (open rhomboid symbols), mammals (closed circle symbols), and reptiles (open circle symbols). Error bars represent standard error.

Each analysis revealed a main effect of the order in which treatment messages were shown (Tables 3A-C), but repetition of treatment messages reduced selected desire to own by a mean of $\leq 7 \%$ across all analyses of bird, mammal and reptile pets, suggesting that the effect size was small.

\section{Respondents' Agreement With Attitude Statements}

Attitude statements were shown only to respondents from Brazil and the USA. Across all attitude/belief statements in the 2018 survey respondents' level of agreement with a given statement correlated strongly with their stated likelihood of future purchase (Figures 4A,B; Table 1).

For statements concerning the source of exotic pets, mean level of agreement with the statements "I can tell if an animal for sale was bred in captivity" and "I'm not worried about buying a pet that was caught from the wild" was low (respectively, 3.39 and 4.21 out of 10; Figure 4A). Odds rations reveal that respondents who had earlier selected the highest purchase likelihoods were, respectively, 5.58 and 4.30 times more likely to agree with these propositions than were non-buyers (Figure 4A; Table 1).

With respect to beliefs about market regulation, respondents disagreed overall with the propositions that "If buying exotic pets was bad for [conservation or animal welfare] shops wouldn't be allowed to sell them" (mean agreement 4.86 and 4.93 for conservation and animal welfare, respectively; Figure 4A) but high likelihood purchasers were 3.10 and 4.12 times more likely to agree (Table 1), such that their mean response was to express agreement with these propositions (Figure 4A). All respondents disagreed with the statement "I can trust traders not to sell animals from illegal sources" (mean agreement 3.33) but high likelihood purchasers were 5.97 times more likely than nonpurchasers to select higher levels of agreement (Figure 4A; Table 1).

Regarding consumer responsibilities, all respondents disagreed with the proposition "It is not my responsibility to make sure exotic pets come from a sustainable source" (mean 3.70/10), but high-likelihood purchasers were twice as likely (odds ratio 1.88) to agree than were non-purchasers (Figure 4B; Table 1). They were also half as likely to agree that "People have a duty to make sure they don't buy pets that come from the wild," although still agreeing with the proposition (odds ratio 0.45; mean agreement 7.72/10; Figure 4B; Table 1).

All respondents selected high agreement with the proposition that buying exotic pets could be bad for species conservation and animal welfare (means of 7.86 and 8.02, respectively) but highlikelihood purchasers were approximately half as likely to select higher levels of agreement than were non-purchasers (Figure 4B; Table 1). Similarly, respondents selected low agreement with "I'm not worried if buying exotic pets decreases wild populations" (conservation) and "I can give an exotic pet a better life than it would have in the wild" (welfare), but high-likelihood purchasers were, respectively, 3.13 and 7.61 times more likely to selected higher agreement with these than were non-purchasers (Figure 4B; Table 1), such that they overall agreed with the latter proposition (Figure 4B).

\section{DISCUSSION}

Respondents from all countries, and across all taxa, demonstrated a reduced desire to own a given exotic pet when shown any of the types of negative treatment statement in this study-but 


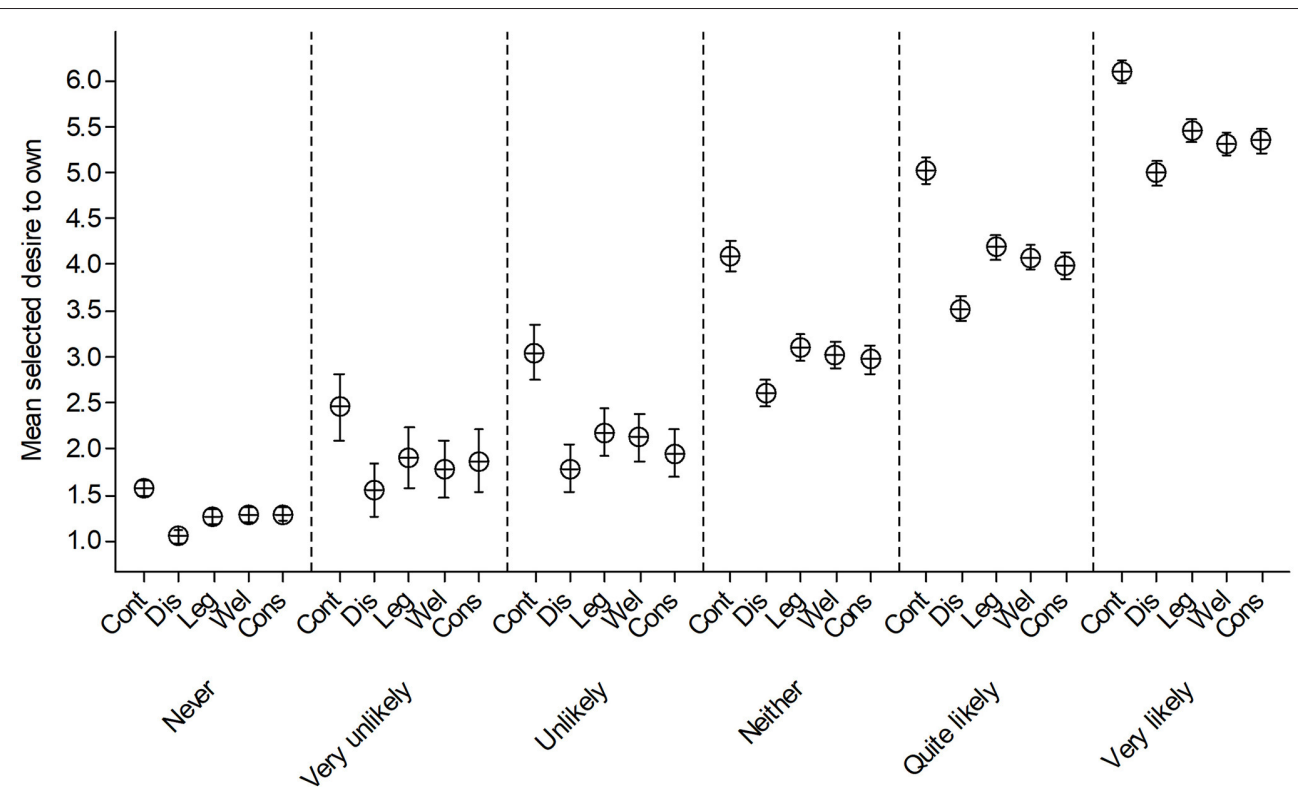

FIGURE 3 | Mean desire to own (on a 1-10 scale) across all taxa and respondents, showing how this, and responses to experimental treatments, varies with respondents' previously stated likelihood of purchasing an exotic in the next 2 years.

effect sizes of treatments were not equal. Statements describing the potential for transmission of zoonotic disease reduced stated desire to own by a mean of $26.9 \%$ relative to controls, compared with $16.1,17.9$, and $18.2 \%$ lower, for legality, welfare or conservation statements, respectively (Figure 2). These findings accord with the principal conclusion of Moorhouse et al. (2017a), that information campaigns focusing on the zoonotic disease consequences of exotic pet ownership were likely to have the greatest effect in lowering purchase desire. Our results confirm that the same conclusion applies to respondents across a range of nationalities and cultural backgrounds, not just to those from culturally Western countries. There was no evidence that respondents from Brazil, China or Vietnam responded to the treatment statements differently either to each other or to respondents from the USA (Figure 2).

A key correlate of respondents' desire to own a given exotic pet was their prior stated likelihood of purchasing an exotic in the next 2 years: the highest likelihoods correlated with desires to own that were $\sim 3-5$ times higher than those who selected the lowest likelihoods of future purchase (Figure 3). The relative effect of treatment statements remained the same across all likelihoods of future purchase: treatment respondents consistently gave stated desires to own that were lower than those of control respondents, albeit that for those with higher prior likelihoods of future purchase the relative stated desires of both control and treatment groups were comparatively higher than for those with lower future purchase likelihoods (Figure 3).

Respondents' stated likelihood of future purchase of exotics was most strongly influenced by a combination of their prior ownership of pets, their nationality and age. Respondents' age had a substantial effect on likelihood of future purchase, which declined across the range of ages in the survey (18-92) by $95 \%$. Similar findings have been shown among purchasers of traditional medicines, with younger respondents expressing a greater desire to buy than older respondents (Coals et al., 2020; Moorhouse et al., 2020). The inverse correlation between age and desire to buy both medicines and pets suggests that older consumers do have different attitudes to the consumption of wildlife products to younger consumers, but we possess no data which would allow us to attribute a cause to the difference. Further work focussing on this topic is required. We have two speculative, and competing, explanations for our finding that prior ownership correlated with a 9-fold increase in respondents' wish to buy further exotics. This association could arise if a set proportion of any population possessed a high desire to own an exotic pet, with these people likely both to have already possessed exotics and to wish to do so in the future. More plausibly, familiarity with exotic pets (e.g., through prior ownership or contact with other pet owners) may increase people's desire to own one. This latter scenario would imply that if exotic pet ownership becomes increasingly common in a society, then increasingly more people would wish to own one. Our data tentatively support this latter interpretation, given that nationality (which, however, only partially acts as a proxy for various cultural and social norms; (Taras et al., 2016) was a primary correlate of desire to own an exotic, with Chinese respondents, for example, being substantially less likely to wish to buy an exotic in the future, compared with respondents from Brazil or the USA, who in turn expressed lower likelihoods than Vietnamese respondents. Taken together the above findings accord with the arguments of Herzog (2014) in suggesting that desire to own certain types of exotic pet is to some extent culturally embedded. As such these desires are likely to be highly 


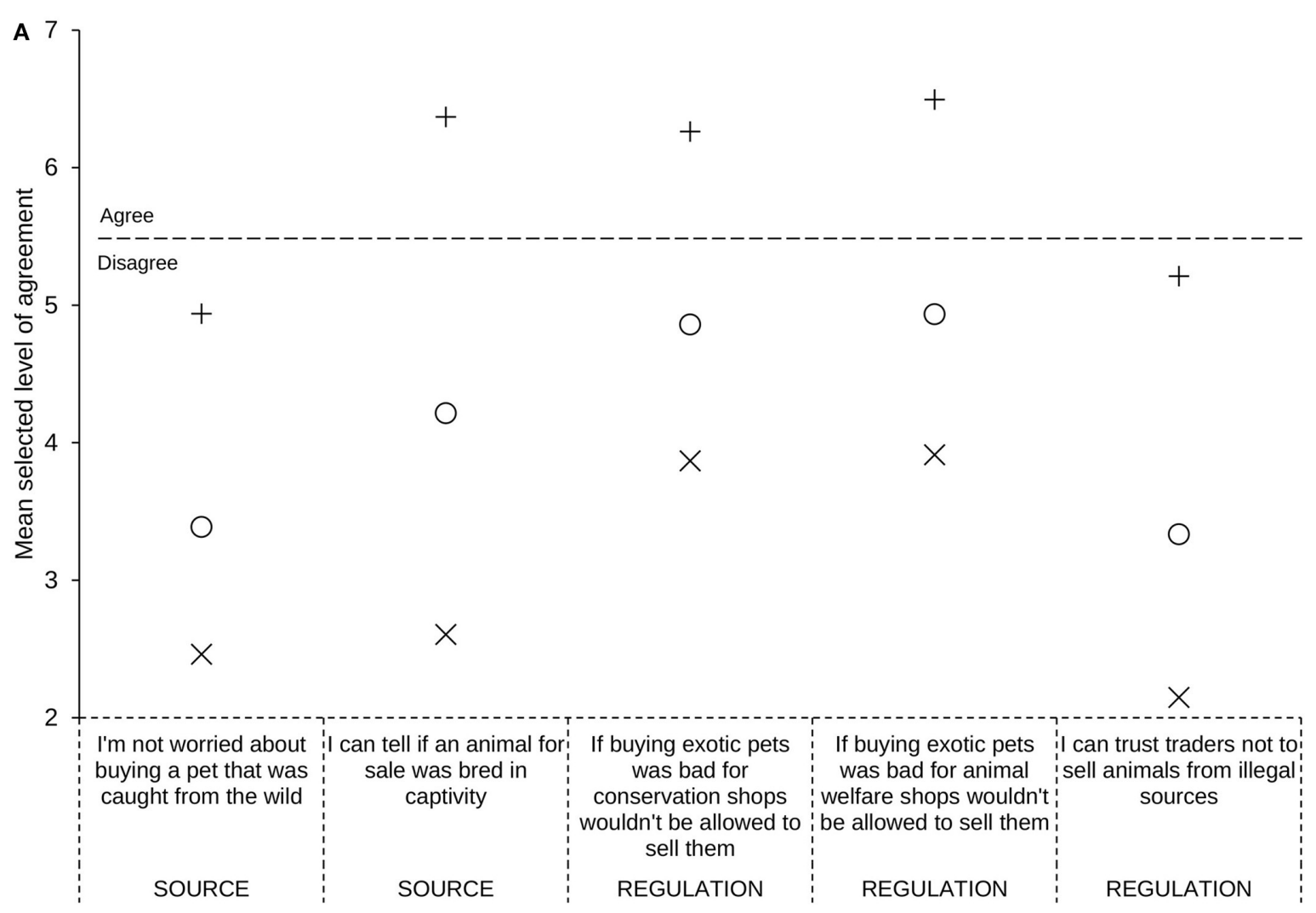

B

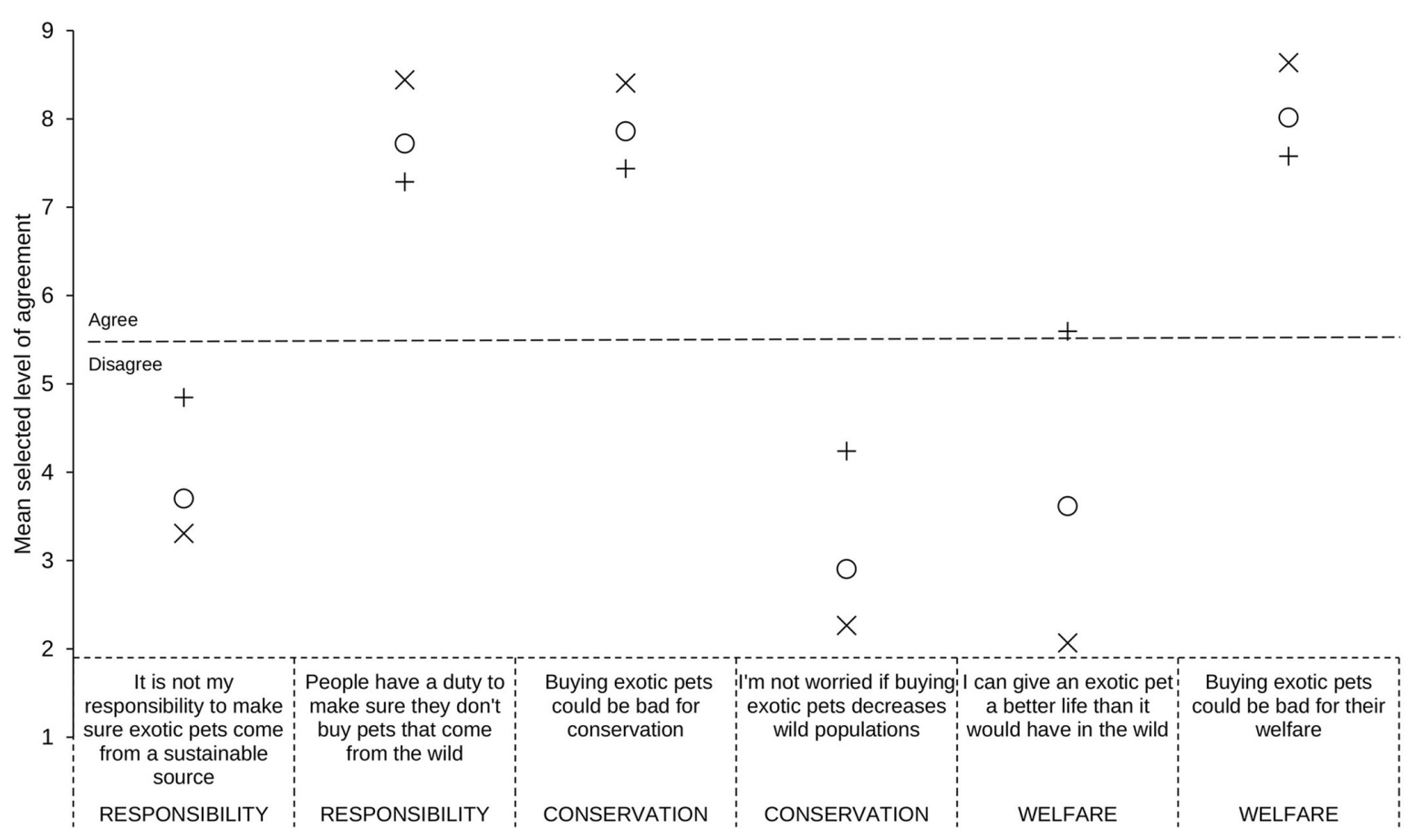

FIGURE 4 | Mean level of agreement (or disagreement) of high likelihood purchasers of exotic pets ("+" symbols), medium likelihood purchasers (open circles) and low likelihood purchasers (" $x$ " symbols) with attitudinal statements describing (A) the source of exotic pets, and the regulation of impacts of the purchase and (B) Consumers' responsibilities, and the conservation and welfare impacts of purchasing exotics. 
TABLE 3 | Factors affecting respondents' selected desire to purchase a given pet, for (A) mammals (B) birds (C) reptile.

\begin{tabular}{|c|c|c|c|}
\hline Source & d.f. & LR statistic & $P$ \\
\hline \multicolumn{4}{|l|}{ (A) } \\
\hline Age & 1 & 140.1 & $<0.001$ \\
\hline Sex & 1 & 6.23 & 0.0125 \\
\hline Country & 3 & 147.1 & $<0.001$ \\
\hline Education & 1 & 1.69 & 0.194 \\
\hline Purchase likelihood & 1 & 1199 & $<0.001$ \\
\hline Treatment & 4 & 465 & $<0.001$ \\
\hline Animal & 7 & 605 & $<0.001$ \\
\hline Order & 1 & 223 & $<0.001$ \\
\hline Income & 1 & -9.47 & $>0.99$ \\
\hline Treatment* Order & 4 & 3.53 & 0.473 \\
\hline Country ${ }^{*}$ Treatment & 12 & 13.0 & 0.366 \\
\hline Purchase Likelihood ${ }^{\star}$ Treatment & 4 & 4.50 & 0.342 \\
\hline \multicolumn{4}{|l|}{ (B) } \\
\hline Age & 1 & 52.9 & $<0.001$ \\
\hline Sex & 1 & 10.5 & 0.00119 \\
\hline Country & 3 & 15.7 & 0.00128 \\
\hline Education & 1 & -0.764 & $>0.99$ \\
\hline Purchase likelihood & 1 & 1188 & $<0.001$ \\
\hline Treatment & 4 & 821 & $<0.001$ \\
\hline Animal & 7 & 1015 & $<0.001$ \\
\hline Order & 1 & 101 & $<0.001$ \\
\hline Income & 1 & 2.28 & 0.131 \\
\hline Treatment* Order & 4 & 2.41 & 0.661 \\
\hline Country ${ }^{\star}$ Treatment & 12 & 57.8 & $<0.001$ \\
\hline Purchase Likelihood ${ }^{\star T}$ Treatment & 4 & 1.76 & 0.780 \\
\hline \multicolumn{4}{|l|}{ (C) } \\
\hline Age & 1 & 131 & $<0.001$ \\
\hline Sex & 1 & 8.64 & 0.00329 \\
\hline Country & 3 & 123 & $<0.001$ \\
\hline Education & 1 & 24.4 & $<0.001$ \\
\hline Likely_purchase2 & 1 & 1276 & $<0.001$ \\
\hline Treatment & 4 & 308 & $<0.001$ \\
\hline Animal & 7 & 2367 & $<0.001$ \\
\hline Order & 1 & 361.12 & $<0.001$ \\
\hline Income & 1 & -34.9 & $>0.99$ \\
\hline Treatment* Order & 4 & -2.05 & $>0.99$ \\
\hline Country ${ }^{\star}$ Treatment & 12 & 25.4 & 0.0128 \\
\hline Likely_purchase2^Treatment & 4 & 2.14 & 0.709 \\
\hline
\end{tabular}

Statistics given to 3 significant figures.

amenable to change (Herzog, 2014), but this would require sufficient people's behavior to be influenced.

Repetition of different treatment types increased their overall effect in lowering respondents' desire to own pets. This effect was, however, minor: respondents rated 15 different animals, but mean desire to own was $<7 \%$ lower for the last animal shown compared with the first. These findings permit the conclusion that having seen one message did not predispose respondents either to disregard the next, or conversely to treat the next message as substantially more serious than would otherwise have been the case. There was also no evidence that this repetition interacted with the type of message: repetition of statements did not have differential effects on different message types. Overall, therefore, we have a high degree of confidence that our experimental design, in testing multiple different animals and messages for each respondent, did not prejudice our results in favor of any given treatment.

Attitudinal questions were asked only of participants from the USA and Brazil, due to the Vietnamese and Chinese respondents being required for a separate, follow-on survey [see Moorhouse et al. (2020)]. Responses to these questions correlated strongly with respondents' stated likelihood of future purchase (Table 1; Figures 4A,B). In particular the mean response of high-likelihood buyers (those who stated they were "quite" or "very" likely to purchase an exotic pet in the future) appear to believe that buying exotic pets from shops would not give rise to negative welfare or conservation outcomes: their mean response to the proposition "If buying exotic pets was bad for [conservation or animal welfare] shops wouldn't be allowed to sell them" was to agree, whereas respondents with low likelihoods (non-buyers and those who chose "quite" or "very" unlikely) and moderate likelihoods ("Neither likely nor unlikely") disagreed (Figures 4A,B). Similarly, high likelihood buyers also agreed with the proposition that they could identify wild animals that had been bred in captivity and that they could provide a better quality of life for an exotic pet than it could have in the wild, while other respondents disagreed. These findings in particular, and responses shown in Figures 4A,B in general, indicate that high-likelihood purchasers possess a set of beliefs that enable them to justify buying exotic pets on the grounds that their purchases would not give rise to negative outcomes for those animals-and indeed may improve those animals' lives.

The trade in wildlife for pets, medicines and luxury items is now the joint largest driver of the global decline in biodiversity (along with agriculture): of the species listed as threatened or near-threatened by the IUCN, $72 \%$ are being exploited at unsustainable rates (i.e., at rates that cannot be compensated for by reproduction or regrowth) for commerce, recreation or subsistence (Maxwell et al., 2016). The conditions in which species are transported and the purposes for which they are used also create substantial animal welfare concerns globally (Baker et al., 2013). As a tool for combating the demand underpinning this trade, social marketing campaigns arguably are not achieving their potential-at least partially due to a lack of reporting of the effectiveness of approaches and correlates of success (Olmedo et al., 2018; Veríssimo et al., 2018; Veríssimo and Wan, 2019). A recent study concluded that of 236 such campaigns, only a quarter reported on outcomes (e.g., changes in the target audience regarding, for example, knowledge, attitudes, or behavior) and $<9 \%$ reported on conservation impacts (Veríssimo and Wan, 2019). Our approach in this study has been to experimentally test which messages are likely to be successful as a step toward improving impacts, by providing data to underpin the initial selection of messaging, so campaigns can focus on those messages most likely to influence consumers' behavior. 
In conclusion, informing potential pet owners of the negative impacts of the purchase, in particular of the potential zoonotic disease impacts, was shown to lower demand for exotic pets. We also speculate that societal norms are likely to influence individuals' desires to own exotic pets. Respondents' nationality, age, and previous ownership of exotic pets all predispose them to be more likely to wish to buy a given exotic, notwithstanding that all of our respondents, regardless of background and prior disposition, reacted similarly to similar information. Taken together our evidence argues that demand reduction approaches on this topic are suitable for application to diverse audiences, but that the reduction in purchase desire of audiences that have a higher underlying disposition toward pet purchase is likely to still result in substantial numbers desiring to buy an exotic (Figure 3). Finally, our study reveals that the respondents most likely to buy pets in the future possess a series of beliefs that could facilitate this purchase while maintaining a self-image of being ethical (e.g., Bazerman et al., 1998; Tenbrunsel and Messick, 2004; Sezer et al., 2015). In particular they believed that shops were well-regulated, and that they were able to distinguish captively-bred from wild caught animals. Future research might investigate whether messaging designed to combat these beliefs may be effective at further lowering purchase desire among high-likelihood purchasers.

On the basis of these results, and those of Moorhouse et al. (2017a), we strongly recommend leveraging consumers' desire to avoid zoonotic disease consequences-especially in the light of the COVID-19 pandemic, which this study preceded (see submitted short communication)- by highlighting the zoonoses each species is known to harbor (see Supplementary Table 1). Our suggestion is not that demand reduction campaigns should indiscriminately invoke fear of disease to achieve their goals but that when consumers are made aware of the existence of genuine, potential disease risks, this awareness negatively influences their desire to acquire particular species. This approach could be used to encourage the substitute purchase of non-exotic species, or to advise that exotics are sourced either from rescue centers or from legitimate captive-breeders in the consuming country, thereby reducing the global demand for wild-caught individuals.

\section{REFERENCES}

Ayling, J. (2013). What sustains wildlife crime? Rhino horn trading and the resilience of criminal networks. J. Int. Wildl. Law Policy 16, 57-80. doi: 10.1080/13880292.2013.764776

Baker, S. E., Cain, R., van Kesteren, F., and Zommers, Z. (2013). Rough trade: animal welfare in the global wildlife trade. Bioscience 63, 928-938. doi: 10.1525/bio.2013.63.12.6

Bazerman, M. H., Tenbrunsel, A. E., and Wade-Benzoni, K. (1998). Negotiating with yourself and losing: making decisions with competing internal preferences Academy of Management. Review 23, 225-241. doi: 10.5465/amr.1998.533224

Bush, E. R., Baker, S. E., and Macdonald, D. W. (2014). Global trade in exotic pets 2006-2012. Conserv. Biol. 28, 663-676. doi: 10.1111/cobi.12240

Challender, D. W., Harrop, S. R., and MacMillan, D. C. (2015). Towards informed and multi-faceted wildlife trade interventions. Glob. Ecol. Conserv. 3, 129-148. doi: 10.1016/j.gecco.2014.11.010

\section{DATA AVAILABILITY STATEMENT}

The raw data supporting the conclusions of this article will be made available by the authors, without undue reservation.

\section{ETHICS STATEMENT}

The studies involving human participants were reviewed and approved by CUREC, Oxford University. Written informed consent for participation was not required for this study in accordance with the national legislation and the institutional requirements.

\section{AUTHOR CONTRIBUTIONS}

TM: conceptualization, methodology, analysis, writing-original draft, review and editing, and funding acquisition. ND'C: writing-review and editing and funding acquisition. DM: writing-review and editing and supervision. All authors contributed to the article and approved the submitted version.

\section{FUNDING}

TM received a grant from World Animal Protection to carry out this research. ND'C occupied a position held jointly held between Oxford University and World Animal Protection. The design, conduct, analysis, interpretation, and conclusion of the study were in no way influenced by the source of funding.

\section{ACKNOWLEDGMENTS}

The study was conducted in close collaboration with Tim Baker and Jon Darby or Touchstone Partners Ltd., for whose expertise and professionalism throughout we are extremely grateful.

\section{SUPPLEMENTARY MATERIAL}

The Supplementary Material for this article can be found online at: https://www.frontiersin.org/articles/10.3389/fevo. 2021.609547/full\#supplementary-material

Challender, D. W., and MacMillan, D. C. (2014). Poaching is more than an enforcement problem. Conser. Lett. 7, 484-494. doi: 10.1111/conl.12082

Christensen, M. R. H. B. (2015). Analysis of Ordinal Data With Cumulative Link Models - Estimation With the R-Package Ordinal. Available online at: https:// cran.r-project.org/web/packages/ordinal/vignettes/clm_intro.pdf (accessed September 22, 2020).

Christensen, R. H. B., and Christensen, M. R. H. B. (2015). Package 'Ordinal': Statista. 2016. Pet Ownership Worldwide in 2016 by Country. Available online at: https://www.statista.com/statistics/961098/worldwide-petownership-by-type-by-country/ (accessed September 22, 2020).

Coals, P., Moorhouse, T. P., D'Cruze, N. C., Macdonald, D. W., and Loveridge, A. J. (2020). Preferences for lion and tiger bone wines amongst the urban public in China and Vietnam. J. Nat. Conserv. 57:125874. doi: 10.1016/j.jnc.2020.125874

Cong, L., Newsome, D., Wu, B., and Morrison, A. M. (2014). Wildlife tourism in China: a review of the Chinese research literature. Curr. Issues Tour. 20, 1116-1139. doi: 10.1080/13683500.2014.948811 
Courchamp, F., Angulo, E., Rivalan, P., Hall, R. J., Signoret, L., Bull, L., et al. (2006). Rarity value and species extinction: The anthropogenic allee effect. PLoS Biol. 4, 2405-2410. doi: 10.1371/journal.pbio.0040415

da Nóbrega Alves, R. R., Nogueira, E. E., Araujo, H. F., and Brooks, S. (2010). Bird-keeping in the Caatinga, ne Brazil. Hum. Ecol. 38, 147-156. doi: 10.1007/s10745-009-9295-5

Dalberg, W. (2012). Fighting Illicit Wildlife Trafficking. Gland: WWF International.

Ding, J., Mack, R. N., Lu, P., Ren, M., and Huang, H. (2008). China’s booming economy is sparking and accelerating biological invasions. Bioscience 58, 317-324. doi: 10.1641/B580407

Dutton, A., Gratwicke, B., Hepburn, C., Herrera, E. A., and Macdonald, D.W. (2013). "Tackling unsustainable wildlife trade," in Key Topics in Conservation Biology 2, eds D. W. Macdonald and K. J. Willis (Malaysia: Wiley-Blackwell), 74-91. doi: 10.1002/9781118520178.ch5

Engler, M., and Parry-Jones, R. (2007). Opportunity or Threat: The Role of the European Union in Global Wildlife Trade. TRAFFIC Europe.

Fernandes-Ferreira, H., Mendonça, S. V., Albano, C., Ferreira, F. S., and Alves, R. R. N. (2012). Hunting, use and conservation of birds in northeast Brazil. Biodivers. Conserv 21, 221-244. doi: 10.1007/s10531-011-0179-9

Grant, R. A., Montrose, V. T., and Wills, A. P. (2017). Exotic: should we be keeping exotic pets? Animals 7:47. doi: 10.3390/ani7060047

Grieser-Johns, A., and Thomson, J. (2005). Going, Going, Gone: The Illegal Trade in Wildlife in East and Southeast Asia World Bank. Washington, DC.

Haken, J. (2011). Transnational Crime in the Developing World. Global Financial Integrity. 32, 11-30.

Harrington, L. A. (2015). International commercial trade in live carnivores and primates 2006-2012: Response to bush et al. 2014. Conserv. Biol. 29, 293-296. doi: $10.1111 /$ cobi.12448

Herzog, H. (2014). Biology, culture, and the origins of pet-keeping. Anim. Behav. Cogn. 2014, 296-308. doi: 10.12966/abc.08.06.2014

Lenzi, C., Grasso, C., and Rizzolo, J. B. (2020). Are exotics suitable pets? Vet. Rec. 186, 459-460. doi: 10.1136/vr.m1303

Maxwell, S. L., Fuller, R. A., Brooks, T. M., and Watson, J. E. M. (2016). Biodiversity: the ravages of guns, nets and bulldozers. Nature 536, 143-145. doi: $10.1038 / 536143 a$

McNeely, J. A., Kapoor-Vijay, P., Zhi, L., Olsvig-Whittaker, L., Sheikh, K. M., and Smith, A. T. (2009). Conservation biology in Asia: The major policy challenges. Conserv. Biol. 23, 805-810. doi: 10.1111/j.1523-1739.2009.01284.x

Moorhouse, T. P., Balaskas, M., D'Cruze, N. C., and Macdonald, D. W. (2017a). Information could reduce consumer demand for exotic pets. Conser. Lett. 10, 337-345. doi: 10.1111/conl.12270

Moorhouse, T. P., Coals, P. G., D'Cruze, N. C., and Macdonald, D. W. (2020). Reduce or redirect? Which social marketing interventions could influence demand for traditional medicines? Biol. Conserv. 242:108391. doi: 10.1016/j.biocon.2019.108391

Moorhouse, T. P., D'Cruze, N., and Macdonald, D. W. (2019). Are Chinese nationals' attitudes to wildlife tourist attractions different from those of other nationalities? J. Sustain. Tour. 27, 12-33. doi: 10.1080/09669582.2018.15 33019

Moorhouse, T. P., D'Cruze, N. C., and Macdonald, D. W. (2017b). The effect of priming, nationality and greenwashing on preferences for wildlife tourist attractions. Glob. Ecol. Conser. 12, 188-203. doi: 10.1016/j.gecco.2017.11.007

Nijman, V., and Shepherd, C. (2009). Wildlife Trade From Asean to the EU: Issues With the Trade in Captive-Bred Reptiles From Indonesia TRAFFIC Europe Report for the European Commission. Brussels.

Olmedo, A., Sharif, V., and Milner-Gulland, E. (2018). Evaluating the design of behavior change interventions: a case study of rhino horn in vietnam. Conserv. Lett. 11:e12365. doi: 10.1111/conl.12365
Pires, S. F., and Moreto, W. D. (2011). Preventing wildlife crimes: Solutions that can overcome the 'tragedy of the commons'. Eur. J. Crim. Policy Res. 17, 101-123. doi: 10.1007/s10610-011-9141-3

Ribeiro, J., Reino, L., Schindler, S., Strubbe, D., Vall-llosera, M., Araújo. M. B., et al. (2019). Trends in legal and illegal trade of wild birds: a global assessment based on expert knowledge. Biodivers Conserv 28, 3343-3369. doi: 10.1007/s10531-019-01825-5

Schultz, P. W. (2002). "Knowledge, information, and household recycling: examining the knowledge-deficit model of behavior change," in New Tools for Environmental Protection: Education, Information, and Voluntary Measures, eds T. Dietz and P. C. Stern (Washington: National Academy Press), 67-82.

Sezer, O., Gino, F., and Bazerman, M. H. (2015). Ethical blind spots: Explaining unintentional unethical behavior. Curr. Opin. Psychol. 6, 77-81. doi: 10.1016/j.copsyc.2015.03.030

Sodhi, N. S., Koh, L. P., Brook, B. W., and Ng, P. K. L. (2004). Southeast Asian biodiversity: an impending disaster. Trends Ecol. Evol 19, 654-660. doi: $10.1016 /$ j.tree.2004.09.006

Statista. (2016). Pet ownership worldwide in 2016 by country. Available online at: https://www.statista.com/statistics/961098/worldwide-pet-ownership-bytype-by-country/ (accessed September 22, 2020).

Stern, P. (2000). Toward a coherent theory of environmentally significant behavior. J. Soc. Issues 56, 407-424. doi: 10.1111/0022-4537.00175

Tao, C.-H., Eagles, P. F. J., and Smith, S. L. J. (2004). Profiling Taiwanese ecotourists using a self-definition approach. J. Sustain. Tour. 12, 149-168. doi: 10.1080/09669580408667230

Taras, V., Steel, P., and Kirkman, B. L. (2016). Does country equate with culture? Beyond geography in the search for cultural boundaries Management. Int. Rev. 56, 455-487. doi: 10.1007/s11575-016-0283-x

Tenbrunsel, A. E., and Messick, D. M. (2004). Ethical fading: the role of self-deception in unethical behavior. Soc. Justice. Res. 17, 223-236. doi: 10.1023/B:SORE.0000027411.35832.53

TRAFFIC International, (2012). Captive Bred or Wild Taken? Traffic International CU.

Veríssimo, D., Bianchessi, A., Arrivillaga, A., Cadiz, F. C., Mancao, R., and Green, K. (2018). Does it work for biodiversity? Experiences and challenges in the evaluation of social marketing campaigns. Soc. Market. Q. 24, 18-34. doi: $10.1177 / 1524500417734806$

Veríssimo, D., Challender, D. W., and Nijman, V. (2012). Wildlife trade in Asia: Start with the consumer. Asian J. Conser. Biol. 1, 49-50.

Veríssimo, D., and Wan, A. K. (2019). Characterizing efforts to reduce consumer demand for wildlife products. Conserv. Biol. 33, 623-633. doi: $10.1111 /$ cobi.13227

Yiwei, H. CGTN (Ed). (2020). Graphics: China's Booming Pet Economy. CGTN. Available online at: https://news.cgtn.com/news/2020--01-22/GraphicsChina-s-booming-pet-economy-NsebhtYvNm/index.html (accessed September 22, 2020).

Conflict of Interest: The authors declare that the research was conducted in the absence of any commercial or financial relationships that could be construed as a potential conflict of interest.

Copyright () 2021 Moorhouse, D'Cruze and Macdonald. This is an open-access article distributed under the terms of the Creative Commons Attribution License (CC $B Y)$. The use, distribution or reproduction in other forums is permitted, provided the original author(s) and the copyright owner(s) are credited and that the original publication in this journal is cited, in accordance with accepted academic practice. No use, distribution or reproduction is permitted which does not comply with these terms. 